\title{
MECHANICAL PROPERTIES AND MICROSTRUCTURES OF REGENERATED CEMENT FROM WASTE CONCRETE
}

\author{
YILENG DU ${ }^{*}$, HONGJUAN ZUO ${ }^{1}$ \\ ${ }^{1}$ University Technical College Portsmouth, 468 London Rd, Portsmouth PO2 9RN, UK
}

\begin{abstract}
It has been a long time since humans started using waste materials in engineering applications. This approach not only reduces the yield of waste, while minimizing the costs of disposal but also limit the cost of new materials. In the field of construction, the reuse of waste concretes has been a strong research in recent years. However the processing of the wastes normally involves complicated processing and lab equipment. In this report we crush and dehydrate waste concretes with normal lab facilities and re-make the cement composites. The waste concretes were crushed and dehydrated at two temperatures, 1280 and $1400{ }^{\circ} \mathrm{C}$. To balance the concentration of silica and lime, extra lime at $28.5 \%$ and $16 \%$ were added to the waste concretes. The resultant materials were evaluated with respect to the chemical composition, mechanical properties, and microstructures. It is concluded that the material dehydrated at $1400{ }^{\circ} \mathrm{C}$ and containing $28.5 \%$ lime presents the best mechanical performance. This report presents a simple and inexpensive method to reuse the waste concretes in applications such as pavements.
\end{abstract}

Keywords: waste concrete, regenerated cement, mechanical properties, microstructures

\section{INTRODUCTION}

As a result of modernization, new consumer behaviors generate waste with exponential increase, in a variety of different divisions of the society. Inappropriate treatment of these wastes, lead to strong negative impacts to the environment. As an applicable and effective method to deal with the waste materials, incorporating the wastes into new products can not only reduce the amount of wastes, but also reduce the cost of industrial manufacturing and production [1, 2]. In the section of construction and buildings, the waste concretes cause many environmental and health issues, while more and more concretes are used these years. In the meantime, the production of cements are facing a shortage of the source materials [3-5]. The global market for construction aggregates is consistently increasing [6-9]. Development has inflicted severe damage on the environment and may endanger its sustainability. The exploitation of natural resources, in particular non-renewable resources, for construction purposes leads to millions of tons of construction and demolition waste every year [10, 11]. Since most countries have no specific processing plan for these materials, they are sent to landfill instead of being reused and recycled in new construction. Of the wastes generated by the construction and demolition activities, a significant amount are the mineral waste or soils, such as excavated earth, road construction waste, demolition waste, waste rocks $[12,13]$. The share of mineral and solidified wastes in relation to the total amount of waste produced was very large [14-18].

A natural approach to solve these pressing problems is to re-use the waste concretes. Whilst recycling is often cited as the best way to manage waste, there are still challenges to utilize waste concretes in construction, such as the uncertainty as to its environmental benefits, low quality of the final product, owing to lack of knowledge [19-

\footnotetext{
* Corresponding author, email: duyilengeric@gmail.com

(c) 2017 Alma Mater Publishing House
} 
23]. Waste concrete materials are being increasingly used in constructions. Targeting engineering applicability, waste concretes should be standardized for the key parameters such as gravel size, specific gravity, water absorption ratio, and crushing values should be determined, and these aggregates should be separated from wood, ceramics, iron, and so on [24-28]. Waste concretes are mostly used as protective barrier and ground-filling material against erosion. In such large-scale projects as rebuilding roads and runways, using waste concretes will reduce the cost of removal of the debris [29-32]. The utilization of waste concretes is increasingly gaining popularity in many countries [33-35]. A lot of labs separates the hardened cement pastes from the waste concretes and then dehydrate the cement pastes at high temperature to generate the recycled cements. However, this method only uses a portion of the waste materials at low efficiency. Waste concretes are crushed and ground by means of different methods so that they could be used as concrete aggregates [36, 37]. Waste concrete can be crushed into different sizes of aggregates. In comparison with normal concrete, Waste concretes have a higher water absorption ratio but a lower specific gravity. The mortar percentage used in waste concrete obtained from crushed concrete of destroyed structures was determined via linear traverse method [38-40]. Workability of concrete wastes is normally not good, and hence water amount often needs to be increased [41, 42]. However, it is inevitable that cement ratio will increase in proportion to water added. Therefore, it would be desirable to obtain finer aggregates in order for a proper workability [43]. It is worth noting that the $\mathrm{CaCO}_{3}$ based aggregates produce materials that share similar chemical compositions with the dehydrated cement paste and hence it may be a viable approach to utilize the dehydrated concretes directly and avoiding the separation step. Currently there are not many results on the utilization of the full composition of waste concretes.

In this paper, we use the waste concretes with $\mathrm{CaCO}_{3}$ based aggregates as the source materials to regenerate cementitious materials. This method is much easier and less cost-consuming in construction activities. We used high temperature kiln to dehydrate the crushed waste concretes and then we studied the chemical composition, mechanical properties and the microstructures of the regenerated concretes. These results will provide guidance on the engineering utility of the waste concretes in construction.

\section{EXPERIMENTAL}

The waste concretes were kindly provided by QUATTRO UK LTD from a source of demolished building. The materials were broken and ground into powders and sieved at $800 \mu \mathrm{m}$. Because the full compositions were dehydrated, the materials contain a large amount of $\mathrm{SiO} 2$ from the fine aggregates. For this reason we added an extra amount of lime of $28.5 \%$ or $16 \%$ in weight to balance the compositions of $\mathrm{Ca}$ and $\mathrm{Si}$. In addition, extra Fe and $\mathrm{Al}$ oxides were also added at about $1 \%$. The mixed raw materials are dehydrated at two different temperatures 1280 and $1400{ }^{\circ} \mathrm{C}$ for about 1 hour. The dehydrated materials are quickly cooled down to room temperature. The processing is presented in Figure 1. No difference was observed on morphology on the materials processed based the two methods.

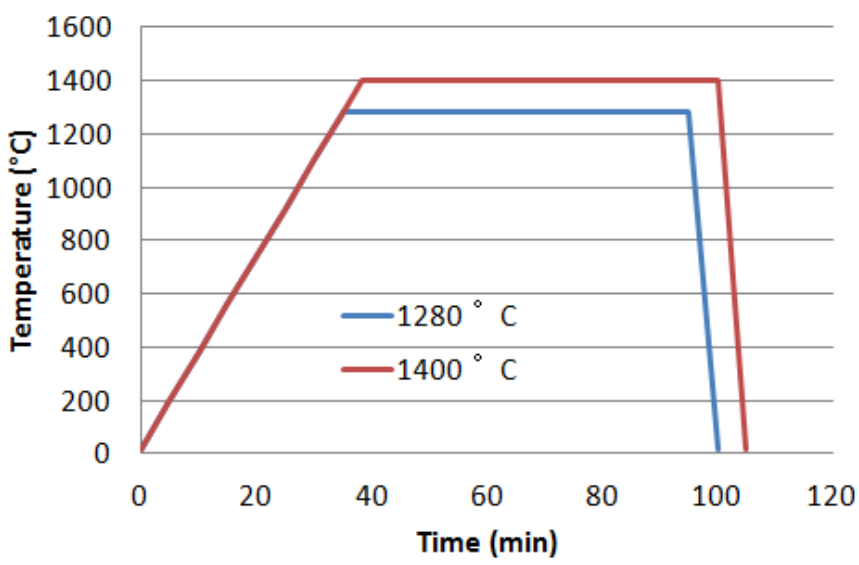

Fig. 1. Temperature processing of the waste concrete.

The chemical compositions were first analysed with x-ray diffraction (XRD) with a Bruker D8 instrument. In total four different materials are prepared to compare these two parameters, as shown in Table 1. Another control sample with no waste concrete was also prepared and studies for comparison purpose. 
The chemical compositions were first analysed with x-ray diffraction (XRD) with a Bruker D8 instrument. In total four different materials are prepared to compare these two parameters, as shown in Table 1. Another control sample with no waste concrete was also prepared and studies for comparison purpose.

Table 1. The four materials with different addition of $\mathrm{CaCO}_{3}$ and dehydration temperatures

\begin{tabular}{|c|c|c|}
\hline Material ID & $\mathrm{CaCO}_{3}$ & Dehydration temperature $\left({ }^{\circ} \mathrm{C}\right)$ \\
\hline 1 & $28.5 \%$ & 1280 \\
\hline 2 & $16 \%$ & 1280 \\
\hline 3 & $28.5 \%$ & 1400 \\
\hline 4 & $16 \%$ & 1400 \\
\hline
\end{tabular}

The mixing procedures follow the ASTM standard C305 - 14. The resulting fresh materials are cast into plastic cylinder molds with the aid of vibration. All samples were sealed and kept at room temperature and demolded on the day of testing's. The samples were subject to compressive and tensile tests at three different ages, 1, 7 and 28 days, with a MTS universal test machine. To understand the mechanism behind the mechanical properties, scanning electron microscopic (SEM) images were taken on the concretes at the age of 28 days.

\section{RESULTS AND DISCUSSION}

\subsection{Chemical composition}

The dehydrated pastes were analysed with XRD and the results are presented in Figure 2. It is clearly seen that the both dehydrated samples, the characteristic peaks of $\mathrm{C}_{3} \mathrm{~S}, \mathrm{C}_{2} \mathrm{~S}, \mathrm{C}_{3} \mathrm{~A}$, and $\mathrm{C}_{4} \mathrm{AF}$ are present, which are consistent with the ordinary clinkers. It is noteworthy that the phases of $\mathrm{CSH}$ and $\mathrm{CH}$ are not seen in the dehydrated materials, which means that the dehydration is completed. While it is challenging to quantitatively calculate the respective compositions of each material based on the relative intensities of the XRD peaks, it is concluded the compositions are similar among the dehydrated paste and the raw clinker. Especially there is no obvious difference between the materials dehydrated at $1280{ }^{\circ} \mathrm{C}$ and $1400{ }^{\circ} \mathrm{C}$.

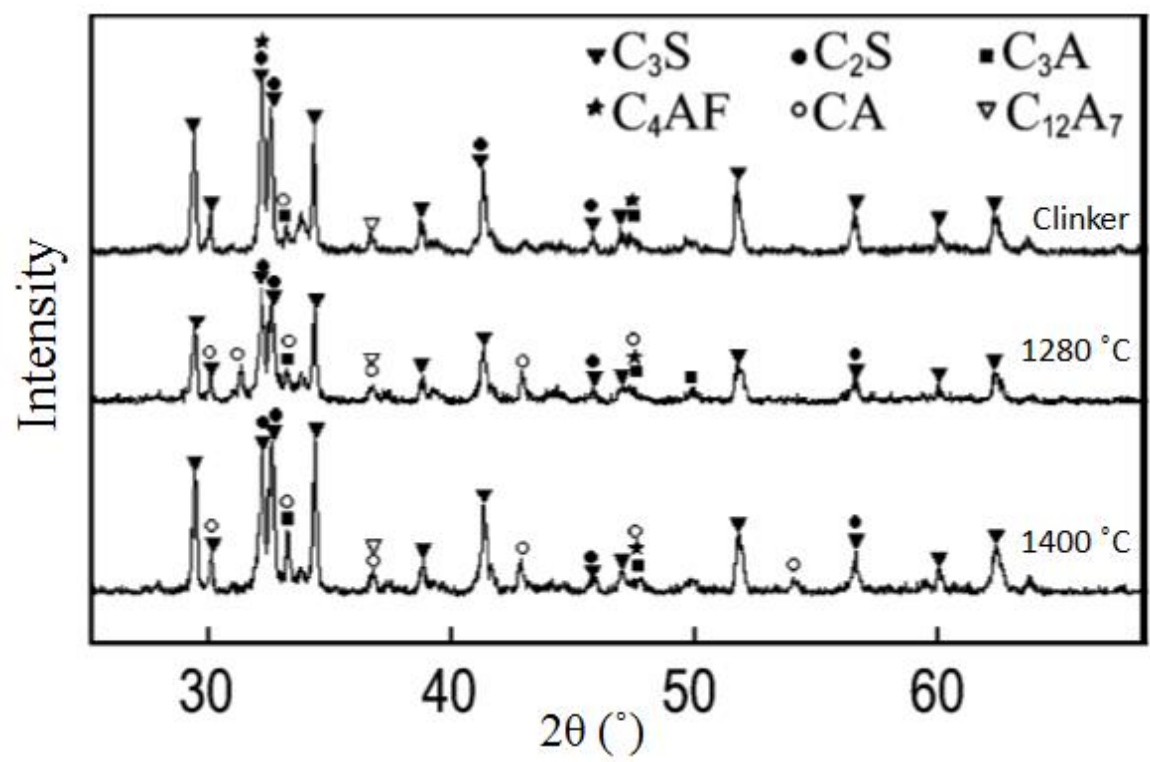

Fig. 2. XRD patterns of the dehydrated cement pastes and the raw clinker.

\subsection{Mechanical properties}

The mechanical properties of the waste replaced samples were compared with studies of compressive tests and tensile tests. The results are also compared with the a control mix without waste replacement. Figure 3 shows the results of compressive strength at the three different ages. As expected, the overall strengths are decreased when the waste materials are used. And with more replacement, the strength are even lower. It is noticeable that the at higher processing temperature $1400{ }^{\circ} \mathrm{C}$, the overall strengths are higher than $1280{ }^{\circ} \mathrm{C}$, which is because at the higher temperature, the waste materials are more fully converted to the clinkers, allowing complete reaction 
between cement and water. An incomplete conversion from hydration products to clinkers may leave the unavailability of reaction spots in the matrix phase, resulting in a non-uniform microstructures. This is the reason causing the premature failures. However it should be noted that the reduction in mechanical properties were not so enormous. Especially for the samples are processed under $1400{ }^{\circ} \mathrm{C}$. The strengths are lowered less than $20 \%$. These materials are apparently feasible for applications such as low level buildings or pavements. The cost will be significantly lower than using raw cement.

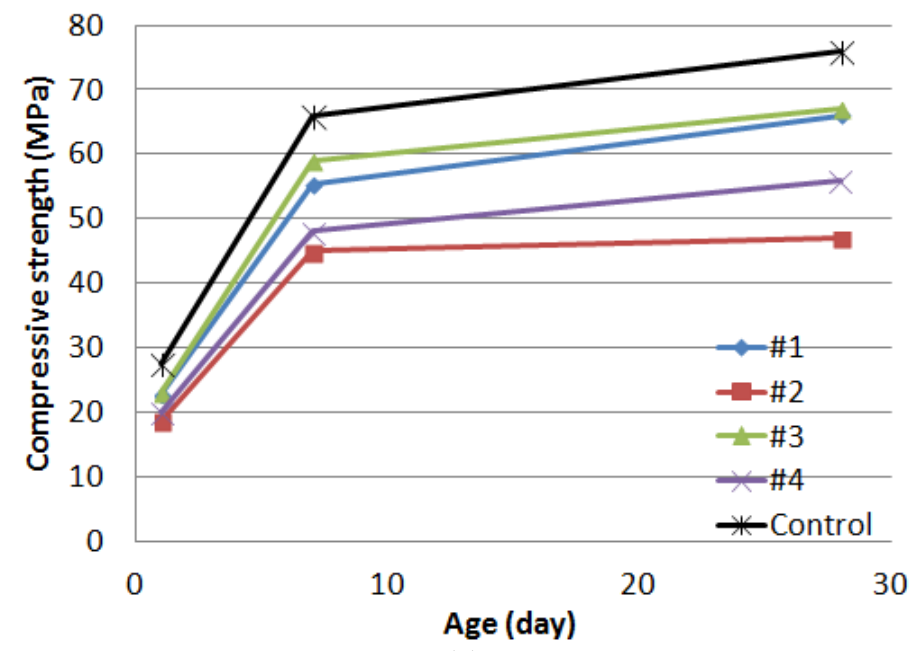

(a)

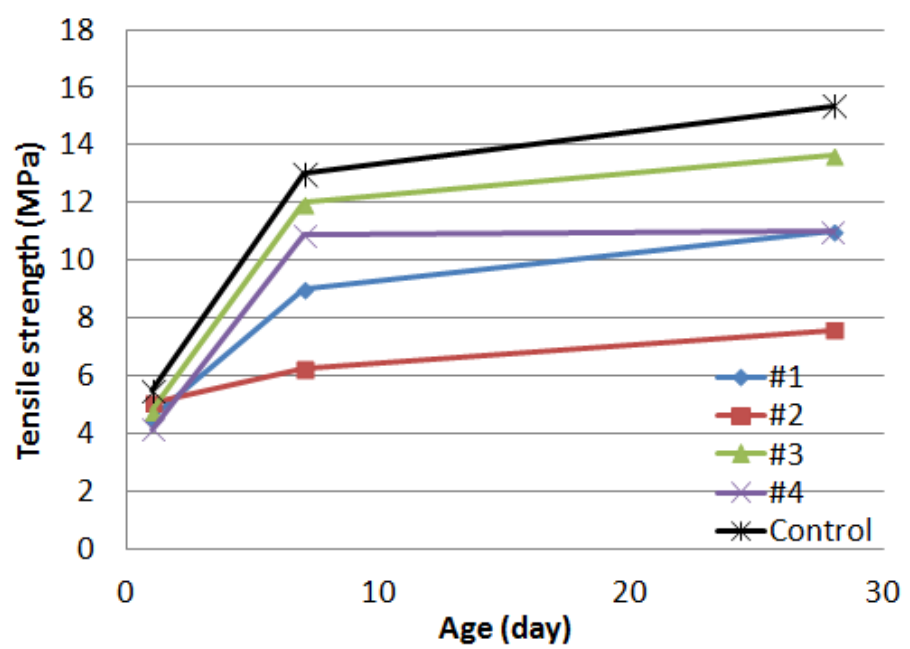

(b)

Fig. 3. a) Compressive strengths; b) tensile strengths of the four mixtures and the control sample.

\subsection{Microstructures}

The SEM images (SEI mode) of the cement paste are shown in Figure 4. The CSH and CH grains are clearly observed in the sample. The morphology of the hydration products with from the waste materials are similar with the normal pastes. In both samples, the $\mathrm{CSH}$ gel can be clearly observed, as well as the $\mathrm{CH}$ plates and $\mathrm{AFt}$ crystals. Comparing these two samples, it is noticed that the amount of the AFt crystals in the waste concrete sample in much less than the control sample, which may be responsible for the lower mechanical properties. It is also noted that in the sample with the regenerated cement, there is a through crack, which may be due to the weak binding between the CSH gels and other hydration products. This is also a viable mechanism to explain the diminished mechanical properties of the concretes from regenerated cement. Other than that, it seems there are no apparent differences in the microstructures between the two samples verifying the validity of using the dehydrated waste concrete to develop new materials. 


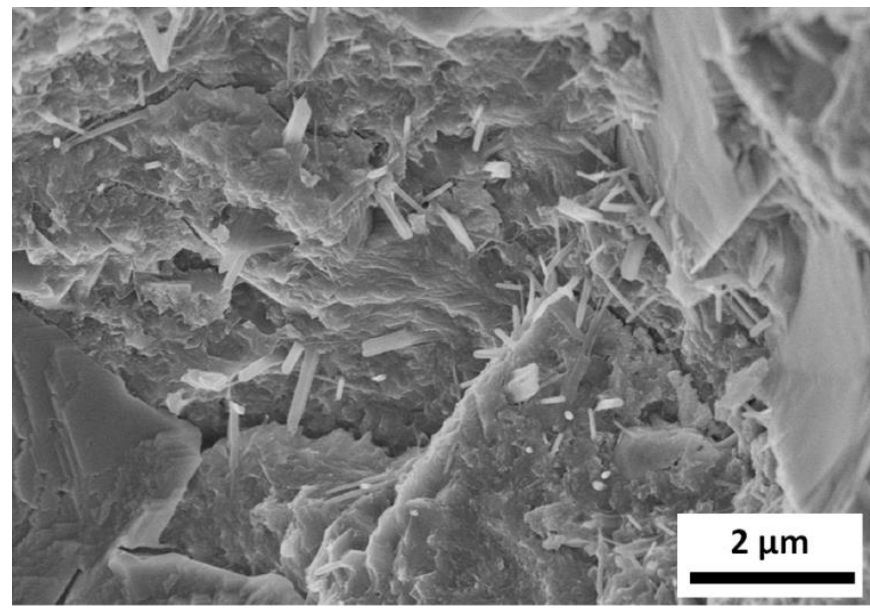

(a)

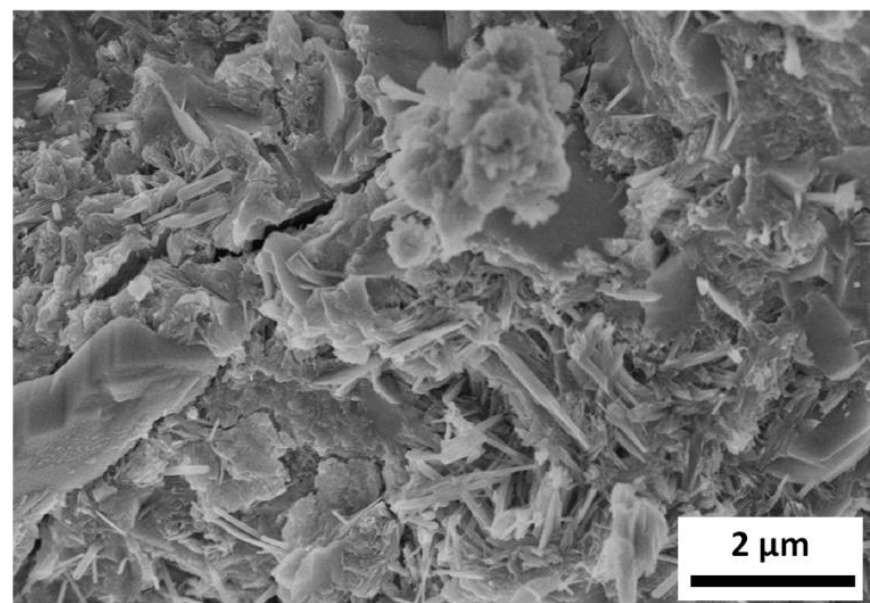

(b)

Fig. 4. The SEM images of hydrated cement paste at the age of 28 days for (a) control sample and (b) sample with dehydrated wastes at $1400{ }^{\circ} \mathrm{C}$.

\section{CONCLUSIONS}

In this work, the waste concretes were processed at temperatures of 1280 and $1400{ }^{\circ} \mathrm{C}$. No difference on morphology was observed on the resultant materials. The resulting dehydrated materials were directly added to mix with cement. The resulting mechanical properties are lower than those of normal concrete samples, based on tensile tests. The microstructures and CSH are also similar with the normal concretes, based on the SEM images. It is applicable to use these waste concretes for construction that does not necessitate high strengths, such as pavement and single-story house. This work provides opportunities of using waste demolished concretes, reducing cost while having a positive impact to the environment.

\section{REFERENCES}

[1] Dong, Y., Li, X., Zhao, Q., Yang, J., Dao, M., Modelling of shrinkage during investment casting of thinwalled hollow turbine blades, Journal of Materials Processing Technology, vol. 244, 2017, p. 190-203.

[2] Dong, Y., Li, X., Zhao, Q., Li, X., Dou, Y., Geometrical modelling to improve the accuracy of drilled cooling holes on turbine blades, International Journal of Advanced Manufacturing Technology, 2017, p. 1-20.

[3] Hu, Z., Lu, W., Thouless, M.D., Slip and wear at a corner with Coulomb friction and an interfacial strength, Wear, vol. 338-339, 2015. p. 242-251.

[4] Hu, Z., Lu, W., Thouless, M.D., Barber, J.R., Simulation of wear evolution using fictitious eigenstrains, Tribology International, vol. 82, 2015, p. 191-194. 
[5] Du, X., El-Khamy, M., Lee, J., Davis, L., Fused DNN: A deep neural network fusion approach to fast and robust pedestrian detection, Applications of computer vision (WACV), 2017 IEEE Winter Conference, 2017, p. 953-961.

[6] Yang, Z., Wang, J., Evans, D., Mi, N., AutoReplica: Automatic Data Replica Manager in Distributed Caching and Data Processing Systems, 1st IEEE International Workshop on Communication, Computing, and Networking in Cyber Physical Systems (CCNCPS 2016), 2016.

[7] Yang, Z., Awasthi, M., Ghosh, M., Mi, N., A Fresh perspective on total cost of ownership models for flash storage in datacenters, 8th IEEE International Conference on Cloud Computing Technology and Science (CloudCom 2016), 2016.

[8] Wykes, M.S.D., Palacci, J., Adachi, T., Ristroph, L., Zhong, X., Ward, M.D., Zhang, J., Shelley, M.J., Dynamic self-assembly of microscale rotors and swimmers, Soft Matter, vol. 12, no. 20, 2016, p. 4584-4589.

[9] Sun, Y., Kang, C., Zhang, A., Liu, F., Hu, J., Zhong, X., Xie, J., Co-delivery of dual-drugs with nanoparticle to overcome multidrug resistance, European Journal of BioMedical Research, vol. 2, no. 2, 2016, p. 12-18.

[10] Cao, Y., Zavaterri, P., Youngblood, J., Moon, R., Weiss, J., The influence of cellulose nanocrystal additions on the performance of cement paste, Cement and Concrete Composites, vol. 56, 2015, p. 73-83.

[11] Cao, Y., Tian, N., Bahr, D., Zavattieri, P.D., Youngblood, J., Moon, R.J., Weiss, J., The influence of cellulose nanocrystals on the microstructure of cement paste, Cement and Concrete Composites, vol. 76, 2016, p. $164-173$.

[12] Cai, W., Wu, B., Wu, N., $2.4 \mathrm{GHz}$ class F power amplifier for healthcare application, International Journal of Computer Science and Information Technologies, vol. 7, no. 3, 2016, p. 1086-1090.

[13] Cai, W., Huang, L., Wen, W., 2.4 GHZ class AB power amplifier for wireless medical sensor network, International Journal of Enhanced Research in Science, Technology \& Engineering, vol. 5, no. 4, 2016, p. 94-98. [14] Wang, L.P., Chen, B.Y., Chen, C., Chen, Z.S., Liu, G.L., Application of linear mean-square estimation in ocean engineering, China Ocean Engineering, vol. 30, no. 1, 2016, p. 149-160.

[15] Wang, L.P., Chen, B.Y., Zhang, J.F., Chen, Z., A new model for calculating the design wave height in typhoon-affected sea areas, Nat Hazar, vol. 67, no. 2, 2013, p. 129-143.

[16] Cai, W., Gong, J., Wu, N., 2.4 GHZ class F power amplifier for wireless medical sensor network, Proceedings of the 2nd World Congress on New Technologies, no. ICNFA 146, 2016, p. 1-7.

[17] Cai, W., Huang, L., Wu, N., Class E power amplifier for wireless medical sensor network, International Journal of Enhanced Research in Science, Technology \& Engineering, vol. 5, no. 4, 2016, p. 145-150.

[18] Cao, Y., Weiss, J., Youngblood, J., Moon, R., Zavattieri, P., Performance-enhanced cementitious materials by cellulose nanocrystal additions, Production and Applications of Cellulose Nanomaterials, 2013, p. 135-136.

[19] Dong, Y., Bu, K., Dou, Y., Zhang, D., Determination of interfacial heat-transfer coefficient during investment-casting process of single-crystal blades, Journal of materials processing technology, vol. 211, no. 12, 2011, p. 2123-2131.

[20] Dong, Y., Zhang, D., Bu, K., Dou, Y., Wang, W., Geometric parameter-based optimization of the die profile for the investment casting of aerofoil-shaped turbine blades, The International Journal of Advanced Manufacturing Technology, vol. 57, 2011.

[21] Dong, Y., Kun, B., Dou, Y., Zhang, D., Determination of wax pattern die profile for investment casting of turbine blades, Transactions of nonferrous metals society of China, vol. 21, no. 2, 2011, p. 378-387.

[22] Cai, W., Shi, F., Design of low power medical device, International Journal of VLSI design \& Communication Systems (VLSICS), vol. 8, no. 2, 2017, p. 1-7.

[23] Cao, Y., Zavattieri, P., Youngblood, J., Moon, R., Weiss, J., The relationship between cellulose nanocrystal dispersion and strength, Construction and Building Materials, vol. 119, 2016, p. 71-79.

[24] Hu, Z., Lu, W., Thouless, M.D., Barber, J.R., Effect of plastic deformation on the evolution of wear and local stress fields in fretting, International Journal of Solids and Structures, vol. 82, 2016, p. 1-8.

[25] Hu, Z., Thouless, M., Lu, W., Effects of gap size and excitation frequency on the vibrational behavior and wear rate of fuel rods, Nuclear Engineering and Design, vol. 308, 2016, p. 261-268.

[26] Wang, H., Hu, Z., Lu, W., Thouless, M.D., The effect of coupled wear and creep during grid-to-rod fretting, Nuclear Engineering and Design, vol. 318, 2017, p. 163-173.

[27] Du, X., Doermann, D., Abd-Almageed, W., A graphical model approach for matching partial signatures, Proceedings of the IEEE Conference on Computer Vision and Pattern Recognition, 2015, p. 1465-1472.

[28] Du, X., Abdalmageed, W., Doermann, D., Large-scale signature matching using multi-stage hashing, Document Analysis and Recognition (ICDAR), 2013, p. 976-980.

[29] Yang, Z., Tai, J., Bhimani, J., Wang, J., Mi, N., Sheng, B., GREM: dynamic SSD resource allocation in virtualized storage systems with heterogeneous IO workloads, 35th IEEE International Performance Computing and Communications Conference (IPCCC 2016), 2016. 
[30] Zhong, X., Bailey, N.A., Schesing, K.B., Bian, S., Campos, L.M., Braunschweig, A.B., Materials for the preparation of polymer pen lithography tip arrays and a comparison of their printing properties, Journal of Polymer Science Part A: Polymer Chemistry, vol. 51, no. 7, 2013, p. 1533-1539.

[31] Wang, C., Zhong, X., Ruffner, D.B., Stutt, A., Philips, L.A., Ward, M.D., Grier, D.G., Holographic characterization of protein aggregates, Journal of Pharmaceutical Sciences, vol. 105, no. 3, 2016, p. 1074-1085.

[32] Cao, Y., Verian, K.P., A VEDA simulation on cement paste: using dynamic atomic force microscopy to characterize cellulose nanocrystal distribution, MRS Communications, vol. 7, no. 3, 2017, p. 672-676.

[33] Chen, B., Escalera, S., Guyon, I., Ponce-López, V., Shah, N., Simón, M., Overcoming calibration problems in pattern labelling with pairwise ratings: application to personality traits, Computer Vision-ECCV 2016 Workshops, 2016, p. 419-432.

[34] Ponce-López, V., Chen, B., Oliu, M., Corneanu, C., Clapés, A., Guyon, I., Baró, X., Escalante, H.J., Escalera, S., ChaLearn LAP 2016: First round challenge on first impressions-dataset and results, Computer Vision-ECCV 2016 Workshops, 2016, p. 400-418.

[35] Zeng, Y., Xie, Z., Zou, J., Hydrologic and climatic responses to global anthropogenic groundwater extraction, Journal of Climate, vol. 30, 2017, p. 71-90.

[36] Wen, R., Umeano, A.C., Dhar, S., Accessing mitochondrial targets using nanocargos, Intracellular Delivery III, 2016, p. 229-254.

[37] Wen, R., Umeano, A.C., Francis, L., Sharma, N., Tundup, S., Dhar, S., Mitochondrion: a promising target for nanoparticle-based vaccine, Vaccines, vol. 4, no. 2, 2016, p. 1-25.

[38] Zhong, X., Sun, Y., Kang, C., Wan, G., The theory of dielectrophoresis and its applications on medical and materials research, European Journal of BioMedical Research, vol. 2, no. 4, 2017, p. 7-11.

[39] Wen, R., Dhar, S., Turn up the cellular power generator with vitamin E analogue formulation, Chemical Science, vol. 7, 2016, p. 5559-5567.

[40] Wen, R., Banik, B., Pathak, R.K., Kumar, A., Kolishetti, N., Dhar, S., Nanotechnology inspired tools for mitochondrial dysfunction related diseases, Advanced Drug Delivery Reviews, vol. 99, 2016, p. 52-69.

[41] Zeng, Y., Xie, Z., Liu, S., Seasonal effects of irrigation on land-atmosphere latent heat, sensible heat, and carbon fluxes in semiarid basin, Earth System Dynamics, vol. 8, 2017, p. 113-127.

[42] Sobolev, K., Lin, Z., Cao, Y., Sun, H., Flores-Vivian, I., Rushing, T., Cummins, T., Weiss, W.J., The influence of mechanical activation by vibro-milling on the early-age hydration and strength development of cement, Cement and Concrete Composites, vol. 71, 2016, p. 53-62.

[43] Wen, R., Umeano, A.C., Dual role of nanoparticle for cancer immunotherapy and imaging, Trends in Immunotherapy, vol. 1, no. 3, 2017. 